\title{
0 que pode um corpo? Instalações interativas e experiências possíveis no cenário contemporâneo
}

\section{Fernanda de Oliveira Gomes}

\section{Resumo}

A partir de questões sobre o corpo, a imagem

e as tecnologias digitais, juntamente com uma análise de instalações interativas que apresentam como característica principal a transformação do espectador em uma espécie de espectador performer, foi identificado um contexto marcado por relações significativas dentro do âmbito artístico que privilegiam situações experimentais e novos sistemas de imagens que projetam o corpo do espectador enquanto imagem da obra. Este trabalho realiza então uma espécie de atualização de relações feitas por Deleuze em seus estudos sobre o cinema, privilegiando as instalações interativas contemporâneas como continuidades de processos cinematográficos. Percebeu-se que o corpo não só experimenta, mas também provoca alterações, a partir da maneira como o espectador se insere em sistemas de dispositivos, principalmente através das atividades criativas possibilitadas nestes sistemas.

Palavras-chave

Corpo. Imagem. Dispositivo. Experiência.

Fernanda de Oliveira Gomes I infernanda@gmail.com

Mestre em Comunicação e Cultura pelo Programa de Pós Graduação em Comunicação e Cultura da Universidade Federal do Rio de Janeiro. Doutoranda do Programa de Pós Graduação em Comunicação e Cultura da Universidade Federal do Rio de Janeiro. Professora substituta da Escola de Comunicação da Universidade Federal do Rio de Janeiro. Bolsista do CNPQ. Artista de instalações interativas.

\section{Um corpo no meio do caminho?}

No centro deste trabalho há um corpo. Um corpo que reage ao mundo que o envolve. Um corpo que vê e que dialoga com o que chega aos seus olhos. Um corpo que ouve e que se movimenta, a partir de estímulos sonoros. Um corpo que fala e que sofre as consequências de suas palavras. Enfim, um corpo que experimenta. Por fora, um invólucro chamado pele, território sensorial que o separa e o conecta ao seu universo interior, complexo organismo marcado por movimentos repetitivos. E no comando de todas estas atividades, o cérebro, invólucro elétrico e cinzento dos processos mentais, gerando incessantemente respostas por todo o corpo. Corpo e mente, conectados, permitem ao humano ser 0 que é: humano.

Em sua reflexão sobre a separação entre corpo e cérebro, Deleuze se refere ao pensamento de Antonioni, que indica dois passos bem diferentes: um para o corpo, e outro para o cérebro. Sua crítica está relacionada à coexistência de um cérebro moderno e de um corpo esgotado. Isso se reflete em um dualismo em sua obra, que 
corresponde aos dois aspectos da imagem-tempo: um cinema que coloca o peso no corpo; e um cinema do cérebro, que descobre a criatividade do mundo e suas potências multiplicadas pelos cérebros artificiais. Mais uma razão, porém, para prestar atenção nos corpos, pois, segundo o próprio Deleuze, "os corpos não estão destinados ao desgaste, tampouco o cérebro à novidade" (DELEUZE, 2005, p. 245). Para ele, o que conta é a possibilidade de um cinema do cérebro que reúna todas as potências, da mesma forma que o cinema do corpo as reunia. A indicação de Deleuze para o cinema é importantíssima para pensarmos como as instalações interativas podem dar um próximo passo, explorando a criatividade corporal na esfera da recepção, a partir da evolução da atividade cerebral, em contato com a tecnologia, na esfera da produção.

É importante pensarmos que tipo de interrupção o corpo poderia representar, segundo alguns autores que discutem essa relação entre corpo e cérebro na contemporaneidade. Paula Sibilia (2002) identifica um direcionamento de saberes hegemônicos contemporâneos para um caminho comum, no qual a materialidade e a organicidade são rejeitadas. 0 corpo se apresenta como um obstáculo, principalmente para a tecnociência, que almeja ultrapassar as limitações biológicas ligadas à materialidade. 0 ideal a ser buscado é ascético, artificial, virtual, imortal.

Alguns artistas, na busca pela transcendência, caminham lado a lado com essas ambições e suas obras apresentam mundos idealizados e simulados, onde é possível experimentar uma não-corporeidade, através do mergulho em ciberespaços. Seria o sublime tecnológico, apontado por Mário Costa (apud SIBILIA, 2002, p. 102) como uma nova forma pós-moderna do sublime kantiano, que transcende os limites da condição humana. Para Roy Ascott (apud SIBILIA, 2002 , p. 102) - um dos artistas mais entusiastas desta linha -, na nova cultura o corpo não tem peso, nem dimensão em qualquer sentido exato e sua medida se dá pela sua conectividade.

Autores como Jonathan Crary (1990) e Paul Virilio (2007) têm dirigido sua atenção para o poder da manipulação inerente às novas tecnologias de visualização e à tendência da imagem digital de separar 0 observador de sua corporeidade. Paul Virilio, por exemplo, afirma que o principal acontecimento do século XX é a superação da matéria. E os cientistas da atualidade reforçam: a definição do ser humano se apoia em seu lado incorpóreo, a mente. Para eles, o corpo é um mero empecilho para a sua expansão ilimitada no tempo e no espaço. A tecnologia superaria tal limitação, concedendo imortalidade à mente na sua hibridização com o software.

\section{0 que pode um corpo?}

Nossa proposta então se volta para 0 corpo e pretende explorar suas relações com imagens e potencialidades, tendo como ponto de partida uma questão fundamental colocada por Espinosa (apud DELEUZE, 2002): 0 que pode um corpo? 
Segundo Deleuze (2002), em sua obra Espinosa:

filosofia prática, o autor foi o primeiro a

valorizar o corpo, que aparece como poder de ser afetado. A ideia de afecção remete à modificação produzida no corpo, a uma relação de causa e efeito. Os corpos que se misturam podem se conciliar e se compor entre si, deslizando por entre, introduzindo-se no meio, constituindo relações de características e valorizando a individualidade e a singularidade.

Na perspectiva de Espinosa, quando acontecem bons encontros entre os corpos, as potências de ser, agir e pensar aumentam. Como a potência de agir é 0 que abre o poder de ser afetado ao maior número de coisas, é bom "aquilo que dispõe 0 corpo de tal maneira que possa ser afetado pelo maior número de modos. Ou então aquilo que mantém a relação de movimento e de repouso que caracteriza o corpo" (DELEUZE, 2002, p. 61).

Este trabalho identifica algumas instalações interativas como situações de bons encontros entre os corpos da obra e os corpos dos espectadores, assim como as imagens da obra e as imagens dos espectadores. Dessa forma, um todo mais potente é constituído, ou seja, uma totalidade superior que inclui todos os elementos. Os artistas são aqueles que organizam estes encontros, compondo relacionamentos vivenciados e procurando aumentar as potências daqueles que estão envolvidos no seu processo. "0 artifício faz parte completamente da Natureza, já que toda coisa, no plano imanente da Natureza, define-se pelos agenciamentos de movimentos e de afetos nos quais ela entra, quer esses agenciamentos sejam artificiais e naturais" (DELEUZE, 2002, p. 129).

A partir de Espinosa, Deleuze afirma que não podemos nos separar de nossas relações com o mundo: 0 interior é somente um exterior selecionado; 0 exterior um interior projetado; a velocidade ou a lentidão das percepções, ações e reações entrelaçam-se para constituir tal indivíduo no mundo. É necessário observar as diversas possibilidades de como essas relações são efetuadas conforme as circunstâncias ou os poderes de ser afetado. Esse tipo de direcionamento pode ser bem útil no momento de identificar as qualidades das instalações interativas. Que possibilidades de relações elas oferecem para seus espectadores? Como elas aumentam a potência de agir dos corpos que as preenchem? Elas permitem uma composição destes corpos com a obra e com os outros corpos que participam de suas interações? Enquanto "desencadeadoras de relações", as instalações interativas podem formar relações mais extensas?

Deleuze (2002, p. 131) afirma que "não se trata mais de utilizações ou de capturas, mas das sociabilidades e comunidades". Aparece aí a noção de rede, que comporta vários usuários/ produtores/emissores. Seguindo este raciocínio, os autores Francisco Varella, Evan Thompson e Eleanor Rosch (2001), chamam a atenção para o processo de cognição não como uma 
atividade individual, mas como um processo coletivo. A nossa inteligência não se reduz a uma interioridade, mas compreende uma partilha. $\mathrm{E}$ o caráter sócio-técnico implica na verdade uma partilha das atividades com os meios técnicos. Um dos grandes desafios para a obra artística é se transformar em um espaço de intensidades, no qual os indivíduos e suas partes variam de infinitas formas. Os dispositivos tecnológicos podem ser vistos, então, como corpos que aumentam a potência de agir dos corpos dos espectadores ativos na obra.

Podemos afirmar que nas obras contemporâneas o corpo não se restringe a ser um articulador de sentido, mas um produtor de sentido. Observamos muito mais uma lógica corporal do que uma lógica significativa. Conseguimos então voltar a Bergson (2006), considerar o corpo como um tipo especial de imagem e a ação, como um ponto de partida em um espaço específico. Segundo o autor, a percepção subjetiva é a parte crescente de indeterminação deixada à escolha do ser vivo, em sua relação variável com as influências mais ou menos distantes dos objetos que 0 interessam. 0 autor caracterizou o mundo externo como um "fluxo universal de imagens". A dedução de Bergson do corpo como um "centro de indeterminação" o leva a reconhecer no corpo fortes capacidades criativas.

Ainda segundo Bergson, na imagem especial que é 0 corpo, destaca-se 0 cérebro, instrumento de análise com relação ao movimento recolhido
- percepção - e instrumento de seleção com relação ao movimento executado. Porém, um corpo não se limita a refletir a ação de fora, ele absorve algo dessa ação. Aí estaria a origem da afecção para Bergson, que seria o conjunto de sentimentos e sensações localizadas em nosso próprio corpo. As afecções se produzem entre estímulos recebidos de fora e movimentos que serão executados, constituindo-se como um convite a agir. Essa poderia ser uma das questões de Bergson para os artistas contemporâneos: que vantagens suas obras podem oferecer? Ou seja, que imagens e sistemas dispositivos efetivamente podem possibilitar experiências significativas para os corpos que as frequentam? E ainda: Como as instalações podem realizar convites à ação através de um envolvimento criativo?

\section{A tecnologia e o retorno sensorial}

Uma investigação que privilegia o corpo e como ele é modificado através das interações facilitadas pelas novas tecnologias é realizada por Mark Hansen (2004). 0 autor faz uma espécie de atualização de alguns conceitos bergsonianos, chamando a atenção para o fato de que Bergson não encontrou muito material relevante na sua teoria da percepção no primeiro cinema, que estava em seu princípio exatamente no momento em que ele estava escrevendo.

Seguindo por este mesmo caminho, Ivana Bentes aponta que a teoria de Bergson "antecipa e reafirma, de certa forma, o que as novas tecnologias interativas vêm explicitando sobre 
o estatuto da percepção enquanto momento privilegiado do agir" (BENTES, 2006, p. 94). Em suas considerações sobre a teoria bergsoniana, a autora destaca que um de seus pontos fundamentais trata da interação entre ver e agir, quando se torna possível misturar imagens do corpo do espectador com outras imagens, ou então fazer da presença do corpo, ou da imagem do corpo um disparador de imagens.

No ponto de vista de Hansen (2004), no cinema o corpo se torna relativamente passivo, constituindo-se como um lugar de inscrição técnica de imagens em movimento ao invés de ser uma fonte ativa que pode formar outros tipos de informações. De um lado está o mundo de imagens performatizadas, tecnicamente montadas como imagens movimento. Do outro está 0 aparato sensório motor do indivíduo que passivamente as correlaciona. Porém, a dimensão sensório-motora do corpo contemporâneo compreende muito mais do que a correlação passiva das conexões entre imagens e serve para outorgar as capacidades criativas do corpo. Hansen se volta então para os recentes desenvolvimentos nas novas mídias e na neurociência para retomar 0 entendimento de Bergson de corporeidade no aspecto de como 0 corpo constrói a informação. 0 autor argumenta que a convergência da mídia aumenta a centralidade do corpo como um formador da informação. A partir do momento em que a mídia perde sua especificidade material, 0 corpo ganha uma maior função de seletor na criação de imagens.
Em algumas instalações interativas, um papel criativo pode ser designado ao corpo, transformando-o na fonte de uma nova forma de aura: a aura que pertence a uma singular atualização na experiência corpórea. Hansen chama de afetividade a capacidade do corpo de se experimentar mais do que ele mesmo e então posicionar seu poder sensório-motor para criar o imprevisível, o experimental, o novo, a partir de sua capacidade de experimentar sua própria intensidade, sua própria margem de indeterminação. Os artistas midiáticos contemporâneos parecem estar adaptando a vocação bergsoniana para as demandas da era da informação: espacializando a imagem e posicionando o corpo do participante em um circuito de informação, as instalações e ambientes criados funcionam como laboratórios para a conversão da informação em imagens corpóreas que podem ser apreendidas. Quando o corpo age para formar uma informação digital, o que ele forma de fato é ele mesmo: sua própria sensação afetiva experimentada em contato com o digital. Seguindo e estendendo o investimento de Bergson na afecção corpórea, os artistas contemporâneos têm operado no deslocamento de uma estética dominante ocular para uma estética háptica enraizada na afetividade corpórea.

\section{Imagens, movimentos, apropriações}

Para entender como as imagens são e devem ser trabalhadas em instalações interativas, é importante considerar os estudos que foram 
feitos para 0 cinema como pontos de partida para novas perspectivas. Este trabalho se lança então em uma série de exercícios de apropriações, retomando considerações e análises fundamentais realizadas por Deleuze em suas obras dedicadas ao cinema: Imagem tempo e Imagem movimento. 0 que propomos a seguir é uma "releitura deslocada" para imagens e experiências de instalações interativas. É um experimento que provavelmente 0 próprio Deleuze aprovaria, já que ele assumidamente se apropriava de outros autores para construir o seu pensamento.

Primeiramente, é importante retomar a ideia de um todo que muda a partir de um movimento, que Deleuze já havia apropriado de Bergson. Este pensamento é essencial na observação da recepção de instalações interativas, já que os espectadores podem afetar não só as imagens, mas também uns aos outros com seus movimentos. Cada movimento assegura a circulação e instaura uma nova perspectiva no conjunto de uma instalação interativa. Cada sub-duração - ou seja, a duração da experiência de cada espectador - vai compor a duração da instalação como um todo, incluindo as durações dos fragmentos de vídeos que estão "armazenados" nas programações que fazem parte dos dispositivos.

É importante ressaltar que Deleuze aponta que Bergson já considerava o cinema incapaz de extrair o movimento puro dos corpos, tendo em vista que o que era levando em conta era apenas o que se passava no aparelho. Ou seja, Bergson já identificava a passividade relegada aos corpos dos espectadores que recebiam as imagens cinematográficas sem poder dar nenhum movimento significativo como resposta.

Ao indicar os três níveis bergsonianos relacionados à imagem em movimento - a determinação dos sistemas fechados, a do movimento que se estabelece entre as partes do sistema e a do todo que muda a partir do movimento -, Deleuze afirma que "[...] há tamanha circulação entre os três que cada um pode conter ou prefigurar os outros" (DELEUZE, 1983, p.44). Porém, se deslocarmos estas relações para os movimentos implicados em instalações interativas, percebemos a possibilidade de uma circulação e uma transformação ainda maiores, pois estão envolvidas não só as imagens préproduzidas, mas também as imagens possíveis que podem ser formadas no próprio ambiente de recepção. Entretanto, os artistas contemporâneos dificilmente conseguem uma experiência que atinja este nível, justamente pela necessidade de organização e composição de imagens, dispositivos e possibilidades de interação. Uma de nossas hipóteses indica que assim como 0 cinema foi evoluindo em experimentações a partir do domínio dos dispositivos próprios de suas dinâmicas de produção e recepção, as instalações interativas também apresentam uma série de aspectos que podem ser mais bem explorados, em seus movimentos evolutivos. 
0 processo de montagem, por exemplo, envolve diversas "sub-montagens", implicadas tanto nas relações possíveis entre as imagens armazenadas, à espera de interações, fusões ou incorporações por parte do espectador, quanto nas próprias relações que podem surgir entre os espectadores no espaço de recepção. Ao analisar o cinema, o próprio Deleuze afirmou que "[...] é preciso ainda que as partes ajam e reajam umas sobre as outras" (DELEUZE, 1983, p.45). Tendo em vista as camadas presentes em uma instalação interativa, podemos já concluir como isso se torna um desafio ainda maior.

Ao instituir a imagem-ação como uma relação entre meios e comportamentos, Deleuze abre novamente um caminho a ser trilhado para as instalações interativas, nas quais são possíveis contínuas variedades destas relações: meios que sempre atualizam qualidades e potências; comportamentos que respondem a estes meios. 0 que podemos observar no conjunto de instalações interativas contemporâneas é que elas ainda se encontram em um estágio bem aquém de suas potencialidades. Ainda há um sub-aproveitamento da imagem em ação e da forma como ela pode se relacionar com o corpo em ação no ambiente da recepção. Por isso a importância de trazer um novo foco ao que Deleuze havia apontado. Por exemplo, que 0 essencial é que "[...] a ação, e também a percepção e a afecção, sejam enquadradas num tecido de relações" (DELEUZE, 1983, p. 246). E também: "A relação (a troca, a dádiva, a devolução) não se limita a cercar a ação, ela a penetra antecipadamente e por todas as partes, e a transforma em ato necessariamente simbólico" (DELEUZE, 1983, p. 247).

\section{Evoluindo na imagem em ação}

Hitchcock foi apontado por Deleuze como o diretor que primeiro concebe a constituição do filme em função de três termos: 0 diretor, o filme e o público. Ao traçar um movimento de relações do espectador com as imagens, Deleuze aponta que no cinema-ação o espectador percebia uma imagem sensório-motora da qual participava mais ou menos, por identificação com as personagens.

A reversão deste ponto de vista foi inaugurada justamente por Hitchcock, que incluiu 0 espectador no filme a partir da possibilidade da instituição de uma relação mental.

\section{E é a partir daí que Deleuze começa a traçar} a crise da imagem ação e o início de um novo cinema: o neo-realismo e o cinema da imagem tempo. 0 que propomos aqui é que esta crise que fez com que 0 cinema buscasse novas relações, principalmente entre tempo e movimento, é recolocada em questão nas instalações interativas, que buscam uma nova perspectiva de ações e reações a partir dos movimentos recebidos pelos corpos dos espectadores. De acordo com Deleuze (1983, p. 252), o cinema era "[...] necessariamente obrigado a atingir 0 acontecimento enquanto está se dando, seja indo de encontro a uma atualidade, seja provocando-a ou produzindo-a". E é isso que efetivamente pode acontecer nas instalações interativas, nas quais 
o imprevisível, a improvisação e o presente vivo apresentam de fato a totalidade aberta que havia sido proposta por Bergson.

Quando o cinema começa a exigir cada vez mais a atividade mental de seu espectador, ele está justamente tentando atingir um nível de interação, porém, uma interação que está muito distante de uma composição proposta por Bergson. 0 pensamento foi a forma de interatividade encontrada pelo cinema. Com as instalações interativas, os encadeamentos situação-ação, ação-reação, excitação-resposta, ou seja, os vínculos sensórios motores que constituíam a imagem-ação (DELEUZE, 1983, p.253), são retomados.

A tentativa do cinema europeu de romper com os limites americanos da imagem-ação era também uma tentativa de unir a imagem, o pensamento e a câmera no interior de uma mesma subjetividade automática, em oposição à concepção demasiado objetiva dos americanos. Imerso nestas imagens, o personagem se via exposto a sensações visuais e sonoras, ou até mesmo táteis e sinestésicas (DELEUZE, 2005, p. 71). Porém, estas sensações visuais e sonoras perdiam seu prolongamento motor. Podemos dizer então que, nas instalações interativas, essas sensações são reconectadas ao prolongamento motor, podendo ainda ganhar um aspecto subjetivo desde que haja uma "[...] separação entre movimento recebido e movimento executado, entre ação e reação, excitação e resposta, imagem percepção e imagem ação" (DELEUZE, 2005, p. 63). Deleuze se refere ao cinema de revelação, no qual a única lógica é a dos encadeamentos de atitudes: as personagens se constituem por seus gestos à medida que 0 filme avança, fabricando-se a si próprias e a filmagem agindo sobre elas como um revelador. Cada progresso do filme permite um novo desenvolvimento de seu comportamento. 0 papel do artista da instalação interativa é bem parecido: fazer emergir estes aspectos criativos, subjetivos e humanos, despertando as potências dos corpos envolvidos no encadeamento formado pela sua obra.

\section{A instalação interativa e a comédia musical}

Na comédia musical, a ação individualizada é vista por Deleuze como fonte criadora do movimento. Em seu "acontecimento", ela começa por oferecer imagens sensório-motoras comuns, nas quais os personagens se veem em situações que pedem ações como respostas. Mais ou menos progressivamente, suas ações e movimentos pessoais se transformam, pela dança, em movimentos de mundo que ultrapassam a situação motora. Dentro desta dinâmica, 0 autor Philip Rosen (2001, p. 346) indica ainda que 0 explícito artifício deste gênero expõe um manifesto à virtualidade e artificialidade cinematográfica, que pode autorizar o espectador a avaliá-la como performance e construção.

A dança surge diretamente como potência onírica que abre o espaço e oferece um mundo 
fluido às imagens: “[...] a dança já não é apenas movimento de mundo, mas passagem de um mundo a outro, entrada em outro mundo, refração e exploração" (DELEUZE, 2005, p. 79). A dança passa a ser um meio de entrar no mundo do outro, de introduzir o personagem no sonho do outro, assim como a relação entre o cenário e 0 movimento possibilita a passagem entre os mundos, o compartilhamento. Na exaltação das situações sensório-motoras, encadeamentos são intensificados, prolongados e multiplicados, formando um conjunto prolífero. Podemos então nos apropriar desta descrição que Deleuze faz do gênero da comédia musical e deslocála para a instalação interativa, que possibilita justamente essa entrada no mundo onírico do outro, seja este outro o conjunto formado pelas imagens armazenadas, à espera da interação, ou o conjunto de imagens formado pela própria experimentação do outro espectador, que faz parte de um conjunto maior, do todo da instalação interativa. Através de situações óticas e sonoras e da possibilidade do prolongamento de ações, nossos movimentos ganham outras dimensões, outros sentidos, e passam a ser como danças improvisadas em um cenário receptivo às transformações de atos ordinários em experiências extraordinárias.

Podemos observar, em algumas instalações interativas que apresentam um caráter extremamente lúdico, experiências que guardam muitas semelhanças com a experiência do indivíduo da comédia musical que redescobre seus movimentos, seu espaço e os objetos que o rodeiam. Uma obra que pode ser citada é a instalação interativa Oups! (fig. 1) de Márcio Ambrósio, que foi exposta e premiada em diversos festivais e espaços destinados à arte interativa, como o Festival Internacional de Linguagem Eletrônica ${ }^{1}$. A obra surgiu do desejo do artista de misturar novas tecnologias e animações tradicionais em uma proposta artística.

Cada sequência animada tem um roteiro e 0 espectador interage e se transforma em um ator desta estória. Quando o espectador entra no espaço da instalação, uma câmera grava sua imagem e a projeta em uma tela diante dele, como um espelho, em tempo e tamanho reais. 0 espectador vê a si mesmo integrado em uma cena que segue seus movimentos, encontrandose imerso em um universo criativo de imagens e sons. As sequências de animação que alimentam esse universo estão armazenadas em um banco de vídeos, sendo que novas animações sempre vão sendo acrescentadas, enriquecendo o projeto e as experiências possibilitadas aos espectadores.

\section{A imagem especular}

Em diversas instalações contemporâneas como a Oups!, podemos observar a formação 


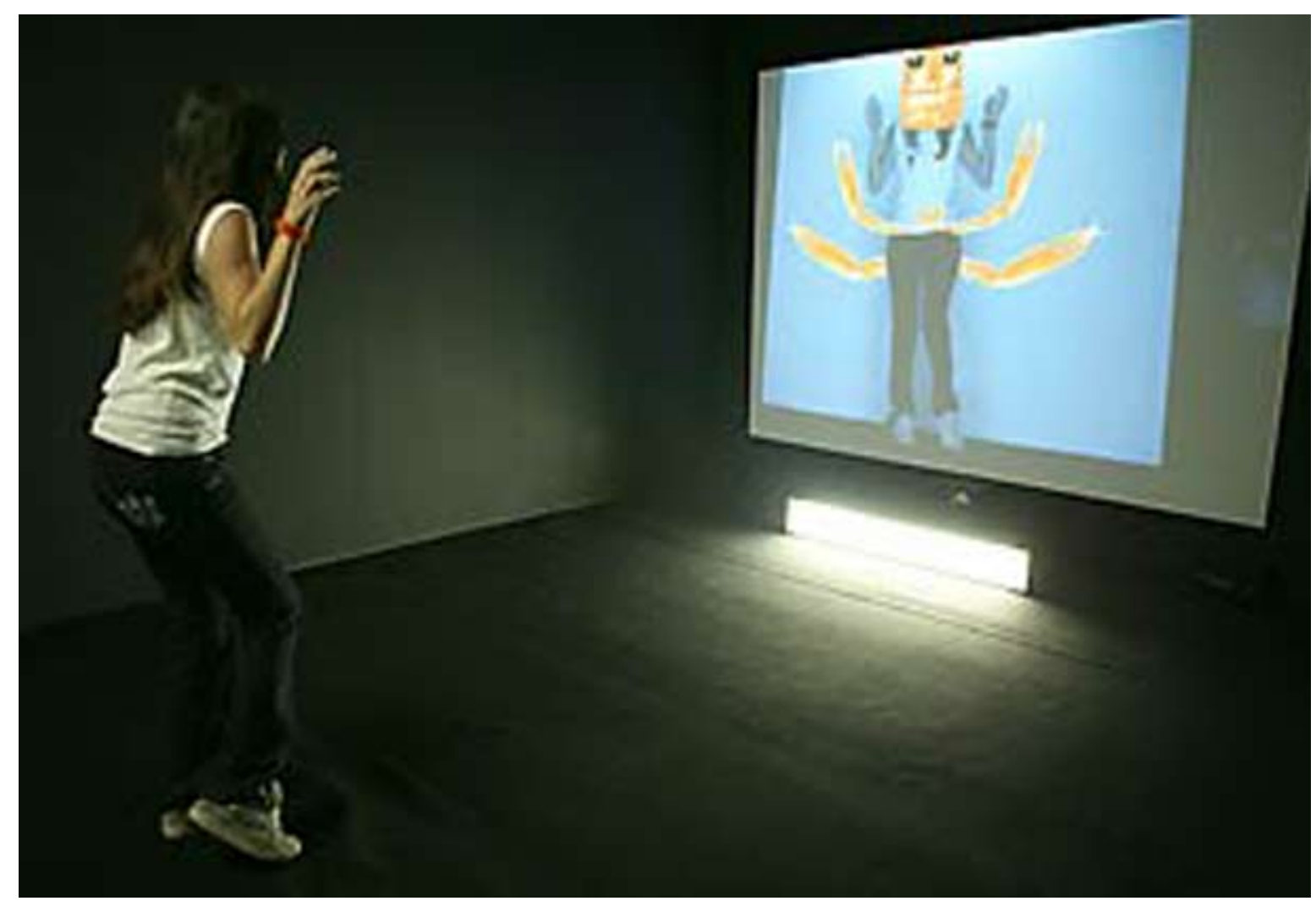

Fonte: http://www.zzzmutations.com/marcioambrosio/index.php?/instalation/oups/

de imagens especulares alteradas. Ou seja, as imagens dos espectadores são projetadas em fusão com imagens pré-programadas ou alteradas simultaneamente, de acordo com os movimentos. Segundo Deleuze, o próprio circuito é uma troca. "Aquele que tomar consciência do contínuo desdobramento de seu presente em percepção será comparável ao ator que desempenha automaticamente seu papel, se escutando e olhando encenar" (DELEUZE, 2005, p. 99). Submeter a imagem a um poder de repetiçãovariação, que foi bastante explorado por Buñuel, possibilita uma sucessão de ciclos, dá lugar a uma pluralidade de mundos simultâneos, a uma simultaneidade de presentes em diferentes mundos. Algo bastante interessante no cinema e que também pode se tornar uma experiência significativa em algumas instalações interativas. A instalação Jump! (fig. 2), de Yacine Sebti, exposta no Festival Internacional de Linguagem Eletrônica de 2007, convida o espectador a estabelecer diálogos com sua própria imagem e com as imagens de outros espectadores.

Como na maioria das instalações interativas atuais, para participar, ele deve seguir algumas "regras". A primeira é "pule para ser gravado". 


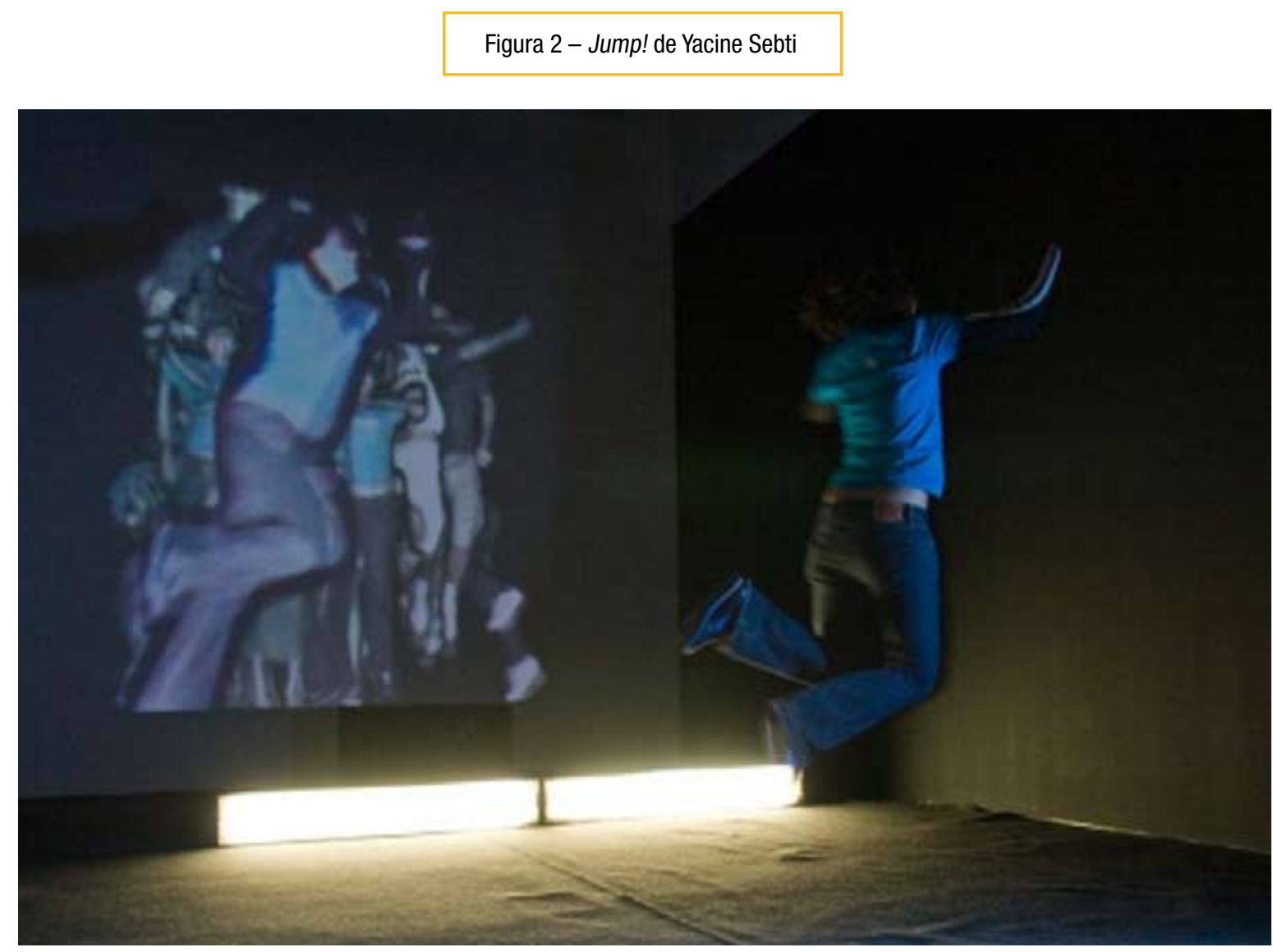

Fonte: http://www.imal.org/yacine/Jump/

Ao entrar na instalação, o espectador encontra sua imagem espelhada sobre a imagem de uma multidão de pessoas que pulam todas juntas. A partir daí, ele poderá interferir nesta imagem: enquanto pula, ele lentamente desloca os pulos dos visitantes anteriores. Além do aspecto lúdico, este trabalho oferece ao visitante uma criação visual do espaço: 0 seu corpo se torna 0 pincel da tela animada.

Ao descrever o cinema, Deleuze oferece o melhor relato para este tipo de instalação. De acordo com 0 autor, em uma descrição orgânica, o real é reconhecido por sua continuidade, mesmo interrompida, pelas leis que determinam as sucessões, as simultaneidades e as permanências. "0 que resta? Restam os corpos, que são forças, nada mais que forças" (DELEUZE, 2005, p.174).

Apesar de as experimentações nos espaços artísticos serem efêmeras, que duram apenas poucos minutos ou até mesmo segundos, elas acabam gerando uma espécie de sensação de conexão, que é uma das principais características da experiência tipicamente contemporânea. Porém, mais uma vez é importante ressaltar que as instalações interativas podem explorar de forma ainda mais rica as relações, conexões e apropriações de imagens e corpos em seus ambientes especulares de recepção. 


\section{$8 \mathrm{~A}$ inscrição do sujeito na imagem}

Em uma convenção que só ocorre no cinema, chama-se objetivo o que a câmera vê, e subjetivo o que a personagem vê. Deleuze observa que o cinema de realidade passou a experimentar objetivamente meios, situações e personagens reais, ao mesmo tempo em que tentava mostrar subjetivamente as maneiras de ver das próprias personagens, a maneira pela qual elas viam sua situação, seu meio, seus problemas. Justamente, o documentário é cada vez mais valorizado, por mostrar o homem comum em suas formas e expressões comuns e incomuns. Para Deleuze, 0 que 0 cinema deve apreender não é a identidade de uma personagem, real ou fictícia, através de seus aspectos objetivos e subjetivos. É o devir da personagem real quando ela própria se põe a "ficcionar". A personagem não é separável de um antes e de um depois, ela se encontra na passagem de um estado a outro. Ao tornar visível cada vez mais os homens comuns, o cinema prepara 0 terreno para a passagem do espectador para o centro da obra.

A pedagogia dos dispositivos de hoje se difere daquela pedagogia típica da modernidade, que ensinava aos espectadores como reagir às imagens, como se comportar e seguir uma disciplina no ambiente da recepção, tendo o cinema como modelo. De acordo com Ivana Bentes (2006), somos constantemente solicitados como performers ou atores. Há uma necessidade explícita de observar e cuidar de nossas atuações em sociedade, viver identidades, experimentar possibilidades performáticas. No mundo contemporâneo, o que se evidencia é a performance, ou seja, os meios ajudam à construção de subjetividades e explicitam a imagem como construto. "Onde somos 'imagens entre imagens' se construindo, experimentando o mundo de muitos lugares, tornados interfaces, mediadores ou ainda figuras de controle" (BENTES, 2006, p. 101).

A relação entre corpo e imagem é artisticamente identificada no encontro da arte da performance com a arte do vídeo, nos anos 50. É possível perceber uma contínua intensificação da concepção da liberdade corporal, da necessidade de uma conexão entre artista, obra, ambiente e público, principalmente com a progressiva midiatização da cultura audiovisual e da reconfiguração da presença. Segundo Fernando Salis (2009, p. 224), "[...] é a própria noção de corporalidade que se refaz". Estas ideias acompanham a atitude de artistas que passaram a valorizar mais o processo do que a obra; mais a ação do que o objeto; mais o corpo do que 0 discurso; e, finalmente, mais a apresentação do que a representação. 0 autor retoma a teoria da performance, que implica em estados de passagem entre ações e comportamentos, a suspensão de normas sociais e 0 convite de transformação de valores feito aos espectadores.

Phillipe Dubois (2004, p. 37) levanta como questão fundamental do processo artístico 
a inscrição do sujeito na imagem, ou seja, a dimensão do humano no artístico, a identificação da personalidade do artista, seu estilo, sua genialidade expressa manualmente na obra.

0 que nos leva a questionar como acontece essa inscrição em instalações interativas. Sim, podemos definir o estilo de um artista a partir de sua proposta. 0 artista mexicano Rafael Lozano-Hemmer, por exemplo, realiza instalações interativas em espaços comuns que convocam uma participação coletiva em grande escala, muitas vezes através de projeções das imagens dos participantes "performando" em tempo real. Porém, o artista se ausenta e coloca em seu lugar o espectador, que ao se inscrever na obra, exibe suas imagens e composições possíveis.

Para Dubois (2004, p. 38), as máquinas como instrumentos são elementos intermediários, inseridas entre o homem e o mundo, dentro do processo de construção simbólica. A técnica fotográfica, por exemplo, intervém no processo de constituição da imagem e 0 gesto humano passa a ser um gesto de condução da máquina. A imagem se faz praticamente sozinha. Porém, essa tendência à "desumanização" do dispositivo de fabricação de imagens, apontada por Dubois, não "engole" todas as propostas artísticas, principalmente quando o espectador é efetivamente convocado a deixar sua marca na obra. É o próprio conceito de "artisticidade" que deve ser revisto, a partir da natureza das relações entre espectadores, artistas e obras. 0 autor afirma que a evolução do maquínico e o problema do humanismo ou da "artisticidade" são bem diferentes, sendo que o desenvolvimento de um não implica na regressão do outro (DUBOIS, 2004, p. 42).

\section{0 corpo é o meio}

0 corpo então persiste em sua materialidade e resiste à digitalização, negando-se a se submeter por completo às modelagens das tecnologias da virtualidade. Como bem disse Francisco Varella, "[...] o cérebro existe no corpo e o corpo existe no mundo" (apud SIBILIA, 2002, p. 103). É neste ponto que a instalação interativa aparece: com 0 corpo em ação bem no centro.

Na perspectiva de Hansen (2004), tecnologias alteram a base da nossa experiência sensorial e afetam drasticamente 0 que significa viver como agentes humanos corporificados, principalmente em relações interativas. 0 artista David Rokeby (1997) resume bem a arte interativa ideal, como uma combinação entre 0 abstrato mundo da linguagem e 0 mundo físico do corpo. Para ele, já que o computador é pura lógica, a linguagem da interação deve ser intuitiva. E já que o computador retira, de certa forma, o indivíduo de seu próprio corpo, é o corpo que deve ser fortemente estimulado. A presença do corpo é reafirmada e responsável pela vida naquele ambiente. As experiências interativas estendem os gestos para além dos limites do corpo, apresentando-se como um outro espaço cognitivo, extensão de nosso espaço sensorial. 
É importante então que tais dispositivos atendam a objetivos artísticos específicos e que não sejam simplesmente "brinquedinhos" novos a serem experimentados. Quando artistas se lançam nessa busca incessante por descobertas técnicas, podem perder a redescoberta do próprio mundo, com tantas novas percepções possíveis sobre gestos e novas sensações a partir da própria realidade. Segundo Hansen (2004), alguns artistas contemporâneos vêm focando em primeiro plano a fundação da visão em modalidades dos sentidos corpóreos: ao catalisar um despertar dos observadores para suas constituições corpóreas, as obras podem ser entendidas como reforços para especificar o que permanece de humano nessa era de convergência digital.

0 interesse aqui então é deixar a tecnologia nos bastidores. Que o participante praticamente não perceba a complexidade tecnológica por trás da obra e que, através de sua interação no espaço artístico, passe por uma experiência realmente significativa, mesmo que efêmera. É o fazer humano que está no centro das obras, não o fazer tecnológico. Mais do que conectado à máquina, 0 corpo está conectado à obra, à sua visibilidade, ao seu aqui e agora e às descobertas possibilitadas na duração de suas experimentações.

Como renegar o corpo se ele é o principal veículo de nossas experiências? Em algumas instalações interativas podemos perceber 0 quanto é rico o encontro dos sistemas artificiais e biológicos, da performance do corpo com a performance dos sistemas.

Um dos artistas mais bem sucedidos nesse sentido é o já citado Rafael Lozano-Hemmer, que possibilita trocas entre espectadores, seus corpos, suas imagens e espaços públicos, em propostas que apresentam grandes complexidades técnicas. Como a obra Body Movies, que transforma 0 espaço público a partir de projeções interativas em grande escala. Diversos retratos fotográficos, previamente tirados nas ruas das cidades onde o projeto é apresentado, são mostrados através de projetores controlados roboticamente. Os retratos aparecem somente dentro das sombras projetadas pelas pessoas que passam pela instalação e suas dimensões dependem da distância em que se encontram das poderosas fontes de luz colocadas no solo. Uma obra que proporciona uma interação entre corpo e espaço público, entre corpo e imagem e entre corpos de transeuntes que se transformam em espectadores e em performers a partir do momento em que se relacionam com os dispositivos espaciais e tecnológicos. 0 projeto teve apoio de seis desenvolvedores, que ajudaram a criar um sistema de seguimento por análise de vídeo que constantemente lançava novos retratos.

Na obra posterior, Under Scan, o artista passou a projetar "vídeo-retratos" em pisos de praças. Em um primeiro momento, estes retratos não podem ser vistos, já que estão apagados por um potente projetor. Quando caminham na área coberta pelo 
sistema dispositivo, as pessoas descobrem os retratos, que são projetados em suas sombras. As sequências de vídeo começam com as pessoas retratadas olhando para um lado. A partir do momento em que aparecem projetados nas sombras dos transeuntes, os retratos se movem e se voltam para eles. Devido à sua complexidade, o projeto teve apoio de um grande número de desenvolvedores. Porém, os dispositivos praticamente não são visíveis e a experiência se torna extremamente orgânica.

Talvez este seja o grande desafio para os artistas contemporâneos que se propõem a criar situações de experiência em suas obras interativas: encontrar este caminho do meio, que também convoca um "estar no mundo", um compartilhamento de experiências. Algo deve, enfim, ser preenchido pelo espectador, que já é parte da obra. 0 espectador é colocado numa posição de produção no jogo artístico e não apenas como um refém de softwares.

Para Couchot (1997), quando o espectador é instalado no centro da obra, ele é convidado pelo artista a adotar uma atitude diferente diante dela. É o corpo inteiro do observador e não mais somente 0 seu olhar que se inscreve na obra, enquanto esta ganha em extensão. A significação da obra passa a depender da intervenção do espectador, a partir da confrontação dramática com uma situação perceptiva. É aí que a obra se abre e 0 tempo de sua criação entra em sintonia com o tempo de sua socialização.
0 "caminho do meio" permite a superação da oposição entre o universo orgânico do corpo e 0 universo mecânico da tecnologia. Não se trata apenas de tornar a natureza artificial, mas também de fazer o processo inverso, ou seja, naturalizar o artificial. Este é o horizonte da coexistência das diferenças, onde predomina a possibilidade de relação, conexão e interação. 0 corpo invadido e dilatado pelas tecnologias surge como um novo modelo de sensibilidade, flexibilidade, inteligência e capacidades comunicativas.

\section{Referências}

BERGSON, Henri. Matéria e memória. São Paulo: Martins Fontes, 2006

BENTES, Ivana. Mídia-arte ou as estéticas da comunicação e seus modelos teóricos. In: BRUNO, Fernanda; FATORELLI, Antônio. Limiares da imagem: Tecnologia e estética na cultura contemporânea. Rio de Janeiro: Mauad, 2006. p. 91-107.

COUCHOT, Edmond. A arte pode ainda ser um relógio que adianta? 0 autor, a obra e o espectador na hora do tempo real. In: DOMINGUES, Diana (org.). A arte no século XXI: a humanização das tecnologias. São Paulo: Fundação Editora da UNESP, 1997.

CRARY, Jonathan. The art of the observer. Massachussets: M.I.T, Cambridge, 1990.

DELEUZE, Gilles. Carta a Serge Daney: otimismo, pessimismo e viagem. In: DELEUZE, Gilles.

Conversações. São Paulo: 34, 1992. p. 88-102. A imagem movimento. São Paulo: Brasiliense, 1983. A imagem-tempo. São Paulo: Brasiliense, 2005. Espinosa: filosofia prática. São Paulo:

Escuta, 2002. 
DUB0IS, Philippe. Máquinas de imagens: uma questão de linha geral. In: DUBOIS, Philippe. Cinema, vídeo, Godard. São Paulo: Cosac \& Naif, 2004.

. Sobre 0 "efeito cinema" nas instalações contemporâneas de fotografia e vídeo. In: MACIEL, Kátia (org.). Transcinemas. Rio de Janeiro: Contracapa, 2009.

HANSEN, Mark B.N. New philosophy for new media. Massachusetts: MIT, 2004.

ROKEBY, David. Espelhos transformadores. In: DOMINGUES Diana (org.). A arte no século XXI: a humanização das tecnologias. São Paulo: Fundação Editora da UNESP, 1997.

ROSEN, Philip. Change mummified: cinema, historicity, theory. London: University of Minnesota Press, 2001.

SALIS, Fernando. Cinema (ao) vivo: a imagenperformance. In: MACIEL, Kátia (org). Transcinemas. Rio de Janeiro: Contracapa, 2009.

SIBILIA, Paula, 0 homem pós-orgânico: corpo, subjetividade e tecnologias digitais. Rio de Janeiro: Relume Dumará, 2002.

VARELA, Francisco; THOMPSON, Evan; ROSCH, Eleanor. A mente corpórea: ciência cognitiva e experiência humana. Lisboa: Instituto Piaget, 2001.

VIRILIO, Paul. Art as far as the eye can see. 0xford: Berg, 2007. 


\section{What can a body do? Interactive installations and possible experiences in the contemporary scenario}

\section{Abstract}

From questions about the body, the image and digital technologies, along with an analysis of interactive installations that have as main feature the transformation of the spectator into a kind of performer spectator, it was identified a context marked by significant relationships in the artistic focus of experimental and new image systems that project the spectator's body as an image of the work. This article develops a kind of update of the relations made by Deleuze in his film studies, focusing interactive installations as contemporary continuities of film processes. It was noticed that the body not only experiences but also causes changes, from the way it lets the viewer fall in system devices, especially through creative activities made possible by these systems.

\section{Keywords}

Body. Image. Dispositive. Experience.

\section{¿Qué puede un cuerpo? Instalaciones interactivas y experiencias posibles en el escenario contemporáneo}

\section{Resumen}

A partir de cuestiones sobre el cuerpo, la imagen y las tecnologías digitales, juntamente con un análisis de instalaciones interactivas que presentan como principal característica la transformación del espectador en una especie de espectador performer, ha sido identificado un contexto marcado por relaciones significativas en la esfera artística que privilegian situaciones experimentales y nuevos sistemas de imágenes que proyectan el cuerpo del espectador como imagen de la obra. Este trabajo realiza una especie de actualización de relaciones hechas por Deleuze en sus estudios sobre el cine, privilegiando las instalaciones interactivas contemporáneas como continuidades de procesos cinematográficos. Ha sido percibido que el cuerpo no sólo experimenta, pero también provoca alteraciones, a partir de la manera como el espectador está inserido en sistemas dispositivos, principalmente a través de las actividades creativas posibilitadas en estos sistemas.

\section{Palabras clave}

Cuerpo. Imagen. Dispositivo. Experiencia. 


\section{Expediente}

A revista E-Compós é a publicação científica em formato eletrônico da Associação Nacional dos Programas de Pós-Graduação em Comunicação (Compós). Lançada em 2004, tem como principal finalidade difundir a produção acadêmica de pesquisadores da área de Comunicação, inseridos em instituições do Brasil e do exterior.

\section{E-COMPÓS I www.e-compos.org.br I E-ISSN 1808-2599}

Revista da Associação Nacional dos Programas de Pós-Graduação em Comunicação. Brasília, v.13, n.1, jan./abr. 2010.

A identificação das edições, a partir de 2008 passa a ser volume anual com três números.

\section{CONSELHO EDITORIAL}

Afonso Albuquerque

Universidade Federal Fluminense, Brasil

Alberto Carlos Augusto Klein

Universidade Estadual de Londrina, Brasil

Alex Fernando Teixeira Primo

Universidade Federal do Rio Grande do Sul, Brasil

Alfredo Vizeu

Universidade Federal de Pernambuco, Brasi

Ana Carolina Damboriarena Escosteguy

Pontifícia Universidade Católica do Rio Grande do Sul, Brasil

Ana Silvia Lopes Davi Médola

Universidade Estadual Paulista, Brasil

André Luiz Martins Lemos

Universidade Federal da Bahia, Brasil

Ângela Freire Prysthon

Universidade Federal de Pernambuco, Brasil

Antônio Fausto Neto

Universidade do Vale do Rio dos Sinos, Brasil

Antonio Carlos Hohlfeldt

Pontifícia Universidade Católica do Rio Grande do Sul, Brasil

Arlindo Ribeiro Machado

Universidade de São Paulo, Brasil

César Geraldo Guimarães

Universidade Federal de Minas Gerais, Brasil

Cristiane Freitas Gutfreind

Pontifícia Universidade Católica do Rio Grande do Sul, Brasil

Denilson Lopes

Universidade Federal do Rio de Janeiro, Brasil

Eduardo Peñuela Cañizal

Universidade Paulista, Brasil

Erick Felinto de Oliveira

Universidade do Estado do Rio de Janeiro, Brasil

Francisco Menezes Martins

Universidade Tuiuti do Paraná, Brasil

Gelson Santana

Universidade Anhembi/Morumbi, Brasil

Goiamérico Felício

Universidade Federal de Goiás, Brasil

Hector Ospina

Universidad de Manizales, Colômbia

Herom Vargas

Universidade Municipal de São Caetano do Sul, Brasil

leda Tucherman

Universidade Federal do Rio de Janeiro, Brasil

Itania Maria Mota Gomes

Universidade Federal da Bahia, Brasil

Janice Caiafa

Universidade Federal do Rio de Janeiro, Brasil

Jeder Silveira Janotti Junior

Universidade Federal da Bahia, Brasil
João Freire Filho

Universidade Federal do Rio de Janeiro, Brasil

John DH Downing

University of Texas at Austin, Estados Unidos

José Luiz Aidar Prado

Pontifícia Universidade Católica de São Paulo, Brasil

José Luiz Warren Jardim Gomes Braga

Universidade do Vale do Rio dos Sinos, Brasil

Juremir Machado da Silva

Pontifícia Universidade Católica do Rio Grande do Sul, Brasil

Lorraine Leu

University of Bristol, Grã-Bretanha

Luiz Claudio Martino

Universidade de Brasília, Brasil

Maria Immacolata Vassallo de Lopes

Universidade de São Paulo, Brasil

Maria Lucia Santaella

Pontifícia Universidade Católica de São Paulo, Brasil

Mauro Pereira Porto

Tulane University, Estados Unidos

Muniz Sodre de Araujo Cabra

Universidade Federal do Rio de Janeiro, Brasil

Nilda Aparecida Jacks

Universidade Federal do Rio Grande do Sul, Brasil

Paulo Roberto Gibaldi Vaz

Universidade Federal do Rio de Janeiro, Brasil

Renato Cordeiro Gomes

Pontifícia Universidade Católica do Rio de Janeiro, Brasil

Ronaldo George Helal

Universidade do Estado do Rio de Janeiro, Brasil

Rosana de Lima Soares

Universidade de São Paulo, Brasil

Rossana Reguillo

Instituto Tecnológico y de Estudios Superiores do Occidente, México

Rousiley Celi Moreira Maia

Universidade Federal de Minas Gerais, Brasil

Samuel Paiva

Universidade Federal de São Carlos, Brasil

Sebastião Albano

Universidade Federal do Rio Grande do Norte, Brasil

Sebastião Carlos de Morais Squirra

Universidade Metodista de São Paulo, Brasil

Simone Maria Andrade Pereira de Sá

Universidade Federal Fluminense, Brasil

Suzete Venturelli

Universidade de Brasília, Brasil

Valério Cruz Brittos

Universidade do Vale do Rio dos Sinos, Brasil

Veneza Mayora Ronsini

Universidade Federal de Santa Maria, Brasil

Vera Regina Veiga França

Universidade Federal de Minas Gerais, Brasil

\section{COMISSÃO EDITORIAL}

Felipe da Costa Trotta I Universidade Federal de Pernambuco, Brasil Rose Melo Rocha I Escola Superior de Propaganda e Marketing, Brasil CONSULTORES AD HOC

João Maia I Universidade do Estado do Rio de Janeiro, Brasil Sandra Gonçalves I Universidade Federal do Rio Grande do Sul, Brasil Mayra Rodrigues Gomes I Universidade de São Paulo, Brasil Gisela Castro I Escola Superior de Propaganda e Marketing, Brasil João Carrascoza I Escola Superior de Propaganda e Marketing, Brasil Luciana Pellin Mielniczuk I Universidade Federal de Santa Maria, Brasil Irene de Araújo Machado I Universidade de São Paulo, Brasil Hermilio Pereira dos Santos Filho I Pontifícia Universidade Católica, Brasil Benjamim Picado I Universidade Federal Fluminense, Brasil Maria Apaecida Baccega I Escola Superior de Propaganda e Marketing, Brasil Rogério Ferraraz I Universidade Anhembi Morumbi, Brasil

Bruno Souza Leal I Universidade Federal de Minas Gerais, Brasi REVISÃO DE TEXTO E TRADUÇÃo I Everton Cardoso EDITORAÇ̃̃ ELETRÔNICA I Roka Estúdio
COMPóS I www.compos.org.br

Associação Nacional dos Programas de Pós-Graduação em Comunicação

Presidente

Itania Maria Mota Gomes

Universidade Federal da Bahia, Brasil

itania@ufba.br

Vice-presidente

Julio Pinto

Pontifícia Universidade Católica de Minas Gerais, Brasil juliopinto@pucminas.br

Secretária-Geral

Ana Carolina Escosteguy

Pontifícia Universidade Católica do Rio Grande do Sul, Brasil carolad@pucrs.br 